\title{
DIE PROBLEMATIEK VERBONDE AAN DIE MAATSKAPLIKE HANTERING VAN DIE GEMOLESTEERDE KIND
}

\author{
G.M. Spies \\ Departement Maatskaplike Werk \\ Universiteit van Suid-Afrika \\ PRETORIA
}

\begin{abstract}
Sextal molestation is most certainly the phenomenon that evokes most repulsion in society at large, and in the helping professions. Since this phenomenon has been exposed by various sources, it is clear at present that professional institutions or people are still not successfully geared to render a non-fragmented service to the culprit, the victin and their various fantilies. It would appear that when services are rendered, the various professions involved in the case are not clear with regard to their various roles. Not only does a lack of knowledge exist regarding the phenomenon dealt with. but also regarding the legal process that is mostly involved in these cases. Almost no identified resource exists in the community which one can approach for help without the emphasis on prosecution. This may enhance the possibility that cases still be kept secret. The question may be asked whether prosecution should be the way to handle sexual molestation, a process during which the involved child cannot be fully protected. Should other forms of help-rendering not be considered?
\end{abstract}

\section{INLEIDING}

Seksuele molestering het die afgelope tyd deur middel van die media op die voorgrond gekom wat meegebring het dat dit al hoe meer die aandag van die geestesgesondheidsprofessies, die teoloë, onderwys- en regsprofessies asook van die algemene publiek begin geniet het. Dit is ook 'n verskynsel wat weersin en vrees by hierdie professies wek. Die redes hiervoor kan onder andere die weersin wees wat so 'n daad wek. Dit kan ook toegeskryf word aan die onkunde wat bestaan oor die verskillende vorme van seksuele molestering met veral die fokus op die implikasie van wat dit vir die kind en sy gesin mag inhou. Vanweë hierdie faktore asook die huiwering en ongemak waarmee professionele persone reageer wanneer hulle diens aan die kind of gesin moet lewer, word aan hierdie gesinne dikwels 'n cul-de-sac-etiket toegeken en weinig intensiewe terapie word aan die gesin gebied. Die verskillende professies en die breë gemeenskap is eerder geneig om hierdie gevalle as hopeloos of onveranderbaar te beskou. Dit is ook die ervaring van die skrywer dat sodra seksuele molestering aan die lig kom, 'n veelvoud persone van verskillende professies by die kinders en hulle gesinne betrokke raak en dat hierdie persone baie duidelik verskillende betekenisse 
aan die molestering heg en daar dus verskillend teenoor die betrokkenes opgetree word. Hierdie verskil in optrede kan 'n klimaat vir gefragmenteerde dienslewering skep.

Die doel van hierdie artikel is dus om

- die problematiek verbonde aan die maatskaplike hantering van die gemolesteerde kind te bespreek en

- om enkele gedagtes te gee oor moontlike alternatiewe optredes of intervensies.

Hierdie artikel is dan ook slegs die konstruksie van die skrywer soos wat sy gebeure volgens 'n bepaalde sistemiese perspektief tydens die hantering van gesinne asook hofsake wat daaruit gevloei het, beleef het.

\section{ENKELE UITGANGSPUNTE}

Seksuele molestering kan vanuit verskillende perspektiewe benader word. Husain, James \& Chapel (1983:591) verduidelik hierdie feit ten opsigte van bloedskande soos voly:

Contemporary psychiatric litcrature approaches incest from the point of view of psychopathology. Some investigations vicw incest as symptomatic of family dysfunction, whilc others have identificd deviant characteristics in the personalities of the involved fathers, daughters, and mothers.

Vanuit bogenoemde aanhaling is dit dus duidelik dat terapeute, maar ook ander professies daarby betrokke tydens die hantering van seksuele molestering, verskillend kan optree. Dit kan benader word as individuele patologie (waar die oortreder gehospitaliseer kan word), as 'n misdaad (waar die oortreder opgesluit kan word), of as 'n gesinsprobleem waarbinne meer as net die oortreder, vader/moeder en kind, 'n rol speel.

Efran et al (1988:28) verduidelik dan ook dat elke persoon dus betekenis gee aan wat hy sien of ervaar en tree dan daarvolgens teenoor hierdie "realiteit" op. Daar bestaan dus nie objektiwiteit en waarheid nie en alles is subjektiewe ervarings van die waarnemer self. In die geval van seksuele molestering wat soveel intense emosies by mense kan wek, behoort die verskillende professies wat met molesteringsake saamwerk, vir mekaar se waarnemings of "realiteite" ruimte te skep. 
3. ENKELE PROBLEME WAT TYDENS DIE BEHANDELING VAN DIE GEMOLESTEERDE KIND DEUR DIE MAATSKAPLIKE WERKER ERVAAR WORD

Die skrywer wat sedert 1984 werk met seksuele molestering en in 'n groter mate met gesinne waarbinne bloedskande voorkom, het al hoe meer tot die besef gekom dat professionele persone se reaksie op seksuele molestering tot die disintegrasie van 'n gesin kan lei. Le Roux (1987:4) sê die volgende hieroor:

Families could easily find themselves in positions of increased risk because of the meaning socicty (i.e. professionals, researchers, or family members) attach to definitions of risk, physical discase or treatment events.

Hoffman \& Long (1969:211-234) het hierdie situasie gedemonstreer en aangetoon hoe gefragmenteerde dienste asook die negatiewe konnotasie en etikettering tot die disintegrasie van die gesin kan lei. Hulle verduidelik dit soos volg:

Many family therapists hold the opinion that nobody can leave the field under negative

connotation. I would add that neither can they change under negative connotation.

Indien die hulpprofessies dus nie in staat is om enige positiewe konnotasie of herformulering van 'n bepaalde situasie te maak nie, sal geen verandering kan plaasvind nie. Om 'n ander positiewe konnotasie of betekenis aan die situasie te gee, is om 'n andersoortige optrede teenoor die situasie moontlik te maak.

Vervolgens word enkele aspekte bespreek wat die taak van die maatskaplike werker in die hantering van die gemolesteerde kind en sy gesin kan strem.

\subsection{Opleiding van maatskaplike werkers}

Die meeste welsynsorganisasies het reeds tot die besef gekom dat maatskaplike werkers wat spesifiek met seksuele molestering werk, spesiaal vir hierdie bepaalde taak opgelei, behoort te word. Dit is egter so dat laasgenoemde weens verskillende faktore nog nie in alle opsigte kon realiseer nie en dat maatskaplike werkers sonder voldoende opleiding met seksuele molestering gekonfronteer word. Hierdie stelling word veral bevestig deur die aantal maatskaplike werkers wat vanuit die praktyk gereeld vir konsultasie en/of opleiding vra. Dit is egter die skrywer se mening dat alle maatskaplike werkers spesifiek opgelei behoort te word ten einde met seksuele molestering te kan werk. Trepper \& Barrett (1989:4) verduidelik dit soos volg:

In our view, a successful incest therapist is one who fecls comfortable dealing with incesteous 
families; is well trained in individual and family therapy theory and techniques; has special training in human sexuality and treatment of sexual disorder; has had formal coursework in family abuse and violence; and, of course, has had formal training and supervision specifically in the treatment of incestuous abuse.

Alhoewel hierdie vereistes verwys na die mees ideale, kan 'n maatskaplike werker sonder opleiding in hierdie verband baie maklik oorweldig of gefrusteerd raak. Opleidinginstansies behoort hierdie nood aan te spreek en die praktyk met opleiding:moontlikhede te ondersteun. Trepper en Barrett (1989: 12) wys daarop dat seksuele molestering van die moeilikste sake is om te hanteer.

Legendre (1986:47) verwys na die terapeut se verantwoordelikheid in hierdie verband soos volg:

On the other hand, counselors need to realize their limitations in this area and make referrals when necessary. Counsclors who make referrals because it is in the best interest of their clients are performing an important function of their profession and show a deep commitment to their clicnts.

\subsection{Gebrek aan toepaslike hulpbronne vir seksuele molestering}

Wanneer 'n maatskaplike werker of enige ander professionele persoon met seksuele molestering gekonfronteer word en hy die behoefte het om met enige ander persoon wat 'n kundige op hierdie gebied is te konsulteer, of om iemand te verwys vir behandeling, is daar weinig hulpbronne om van gebruik te maak. Hulpbronne wat deur sodanige kundiges beman kan word, kan verligting bring vir die persoon in die praktyk wat nie oor gespesialiseerde opleiding beskik nie en kan sodoende van groot waarde wees. Hierdie hulpbronne se funksie kan tweërlei van aard wees, naamlik behandeling maar ook opleiding. Die howe bevind hul tans in 'n dilemma tydens vonnisoplegging by seksuele molesteringsake, aangesien daar nie juis 'n ander alternatief as tronkstraf bestaan nie. Laasgenoemde is gedurende 1990 deur die hooflanddros in Durban, mnr. Augustyn, soos volg verduidelik: "Daar bestaan geen ander hulpbron tussen die hof en die gevangenis waarheen die oortreder en ook sy gesin vir behandeling verwys kan word nie." Hy het verder gegaan deur te noem dat hierdie verantwoordelikheid nie aan 'n enkele persoon as terapeut oorgedra kan word nie. 'n Behandelingseenheid vir seksuele molestering is hier 'n duidelike behoefte en moontlik die antwoord. So 'n behandelingseenheid kan bydra tot die voorkoming van totale gesinsdisintegrasie wat veral deur gevangenissetting van 'n ouer in die hand gewerk kan word. 


\subsection{Die beskerming van 'n gemolesteerde kind}

Met die bekendmaking van seksuele molestering bestaan die moontlikheid deurentyd dat 'n krisis kan ontstaan en behoort die saak onmiddellik aandag te kan geniet. Daar word gewoonlik van terapeute verwag om te besluit of die kind in die gesin mag aanbly en of verwydering uit gesinsverband moet plaasvind. Alvorens so 'n besluit geneem kan word, behoort 'n deeglike evaluering van die gesinsisteem gedoen te word. Legendre (1986:49) wys daarop dat die terapeut dan eers in staat sal wees om 'n besluit in belang van die betrokke kind te kan neem. Hy verduidelik verder dat gesprekke nie net met die kind nie, maar ook met die hele gesin gevoer moet word. Dit bly egter 'n moeilike besluit om te neem. Die volgende aspekte kan wel in aanmerking geneem word wanneer 'n besluit geneem moet word:

- Die verwantskap van die molesteerder kan bepaal of die kind in die gesin kan aanbly of nie. Indien dit iemand buite gesinsverband is en die betrokke kind se gesin emosioneel sterk genoeg is om hom te ondersteun, bestaan daar geen rede vir 'n verwydering nie. Indien bloedskande plaasgevind het en dit bekend is aan die res van die gesin wat sterk genoeg is om hierdie kind teen verdere molestering te beskerm, kan oorweeg word om die kind ook in gesinsverband te hou. Legendre (1986:50) noem dat in laasgenoemde omstandighede oop kommunikasiekanale binne die gesin'n noodsaaklikheid behoort te wees.

- Indien geweld en aggressie by seksuele molestering betrokke was en die kind se lewe daardeur bedreig word, kan geensins oorweeg word om die kind in gesinsverband te hou nie. Indien die molesteerder verwyder word en die res van die gesin weer eens die betrokke kind kan ondersteun, sou dit raadsaam wees om die kind eerder in gesinsverband te hou. Justice \& Justice (1979:135) verduidelik dat wanneer 'n kind uit gesinsverband verwyder word, kan hy of sy dit as 'n strafmaatreël beleef en dit vertolk dat hy of sy vir die molestering verantwoordelik gehou word.

- Die ouderdom van die kind kan ook 'n faktor wees om mee rekening te hou. Dit het dikwels in die skrywer se werk met bloedskandegesinne gebeur dat kinders verduidelik het dat daar net met volwassenes oor hul saak gepraat word en nie met hulleself nie. Indien ' $n$ kind oud genoeg is om deel van die besluitingnemingsproses te wees, behoort so 'n kind se behoeftes aangehoor te word. Indien 'n kind dan nog steeds 'n onrealistiese besluit neem wat risiko's kan inhou, is die geleentheid dan geskep om die implikasies daarvan te bespreek en dan saam met die kind en sy gesin 'n ander besluit te neem. 
- Wanneer die gesin op eie inisiatief die molestering bekend maak, sou dit fataal wees indien die terapeut sonder inagneming van die res van die gesin op ' $n$ verwydering van die kind besluit. Dit gebeur dat 'n kind of ouer soms gaan "hulp" vra en dan "straf" ontvang. Wanneer dit gebeur, bring dit skok by gesinne mee en hul kan dikwels hul vertroue in die hulpprofessies verloor. Behandeling hierna is feitlik buite die kwessie, aangesien daar volkome vertroue tussen die gesin en die terapeut moet bestaan. Trepper \& Barrett (1989:31) bevestig dit soos volg:

We, however, have found that a punishment context usually results in increased resistance on the part of the family, which leads to an increase in a punitive therapeutic posture, which leads to more resistance, and so on.

\subsection{Samewerking tussen die verskillende sisteme wat by die gesin betrokke raak}

Met die bekendmaking van seksuele molestering is dit ' $n$ bekende feit dat daar ' $n$ groot aantal persone van verskillende professies betrokke raak. Dit gebeur soms dat hierdie persone in twee kampe verdeel raak en in konflik met mekaar kom weens die verskillende verwysingsraamwerke wat bestaan. Die gevolg hiervan kan wees dat die gesin ook hulself die stryd aansê teen die voorstanders van gevangenisstraf, en hul opnuut self beskerm. Hierdie situasie kan enige behandelingstrategie strem deurdat die terapeut ook in 'n posisie van "vir" of "teen" geplaas kan word, en dus nie 'n neutrale posisie kan inneem nie (Le Roux, 1987:5). Wanneer al hierdie sisteme volgens hul eie betekenisse met ' $n$ gesin onderhandel en die gesin teenstrydighede tussen die verskillende professies se menings identifiseer, kan dit hul verwar en selfs vertroue laat verloor in die terapeut wat ook 'n professionele sisteem verteenwoordig. Om hierdie aspek verder te verduidelik word 'n gevallestudie van 'n bloedskandegesin bespreek 


\subsubsection{Gevallestudie B}

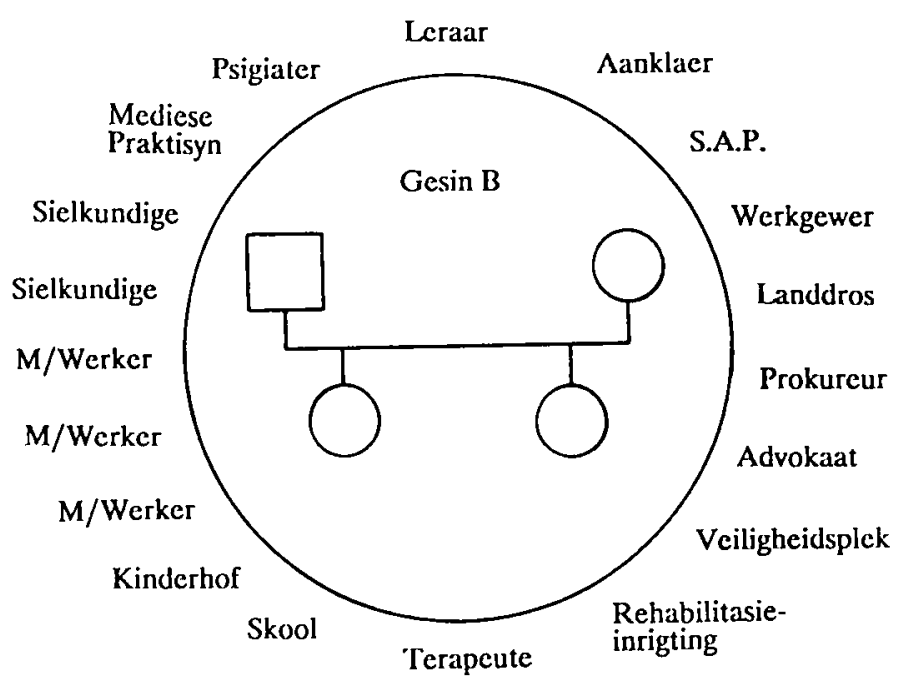

Daar was aanvanklik 18 verskillende persone wat verskillende professies verteenwoordig het by die gesin betrokke voordat die skrywer deur die gesin se advokaat genader is ten einde die gesin te evalueer en hom tydens die regsproses van deskundige raad te bedien. Op hierdie stadium het dit gelyk asof die gesin en veral die vader nie meer hul samewerking aan die professionele span wou gee nie - iets wat weer deur laasgenoemde geïnterpreteer is as weerstand en ontkenning. Op hierdie stadium was die ondersoekproses alreeds plus-minus vyf maande aan die gang en was dit steeds onduidelik watter faktore moontlik tot die bloedskandeverhouding aanleiding kon gee. Deurdat die skrywer 'n neutrale en nie-veroordelende posisie teenoor die gesin ingeneem het, was hul bereid om haar te vertrou. Soos wat die terapeutiese proses gevorder het, het die gesin met die nodige ondersteuning hul eie verduideliking vir die bloedskande wat plaasgevind het, ontdek en gekonstrueer. Die gesin het sonder twyfel die skrywer as "vir" hulle beskou en met die uitsondering van hul regsverteenwoordigers, die res van die persone as "teen" hulle beleef. 
Die skrywer is dadelik in 'n opposisionele posisie geplaas wat meegebring het dat sy haar neutrale posisie verloor het. $\mathrm{Na}$ 'n moeisame en langdurige proses van onderhandelinge met die ander lede van die hulpprofessies om vir eers te onttrek, kon die terapeutiese proses weer voortgaan. Dit was in elk geval die keuse van die gesin gewees om nie met enige ander terapeute saam te werk nie. Deurdat laasgenoemde persone volgens hul eie verwysingsraamwerke ook vir hierdie gesin en veral die betrokke kind omgegee het, is hul met die toestemming van die gesin voortdurend op hoogte van enige vordering gehou. In die geval van hierdie gesin het die regsproses ongeveer 25 maande geduur. Hierdie uitgerekte tydperk kan deels toegeskryf word aan fragmentering van dienste maar ook aan 'n negatiewe atmosfeer waarbinne die gesin nie vertroue, begrip en ondersteuning kon vind nie. Die vraag kan onwillekeurig gevra word of daar werklik in so'n situasie in belang van 'n kind opgetree kan word. Palazolli et al (1980:34) benadruk die feit dat 'n terapeut deurentyd 'n neutrale en nie-opposisionele posisie moet inneem. Nadat 'n meer positiewe terapeutiese konteks vir die gesin geskep is, kon die vader skuld aan die bloedskandeverhouding erken en sy berou aan die gesin oordra. Hy is na 'n appèlsaak nie gevangenisstraf opgelê nie, maar die geleentheid gegun om saam met die gesin te herstel. Die gesin ontvang steeds terapie op 'n vrywillige basis.

\subsection{Blootstelling van 'n kind aan die regsproses tydens 'n strafsaak}

Met die aanmelding van seksuele molestering word daar oor die algemeen van die professionele persoon verwag om dit by die polisie aan te meld. Aangesien laasgenoemde impliseer dat 'n kind moontlik in die strafsaak moet getuig, het professionele persone soms twyfel of dit in belang van die kind en sy gesin kan wees. Dit gebeur egter dikwels dat wanneer 'n ouer tydens 'n verhoor gevangenisstraf opgelè word, die kind wat "teen" die ouer getuig het die verantwoordelikheid vir die gesin se verlies aanvaar en skuldgevoelens ontwikkel. Sou die gesin disintegreer, kan die res van die gesin so 'n kind ook as die skuldige uitwys. Die moontlikheid dat die gereg betrokke kan raak na die bekendmaking van die probleem, bring soms twyfel by 'n kind of hy of sy moet praat al dan nie. Swanson \& Biaggio (1985:671) bevestig dit so:

The punitive focus of the judical system also serves to silence many victims who choose to endure the incest rather than prosecute their father.

Vanuit eie praktiese ervarings kan getuig word dat kinders die stelling gemaak het dat hul hofoptrede meer traumaties as die seksuele molestering was. Die feit dat die terapeut ' $n$ kind in die hof moet bystaan, kan deur die gesin waarvan hierdie kind deel is, ervaar word asof sy "teen" hulle gedraai het. Die behandelingsprogram kan ernstige skade berokken word aangesien die vertrouensverhouding tussen terapeut en gesin beskadig word. 


\section{DIE HUIDIGE REGSTELSEL EN SEKSUELE MOLESTERING}

As gevolg van die weersin wat seksuele molestering by die gemeenskap wek, is laasgenoemde geneig om die verwagting te stel dat die kind in geval van bloedskande onmiddellik uit die gesin verwyder moet word en die vader gevangenisstraf opgelê moet word.

In die geval van seksuele molestering buite die gesin behoort die oortreder ook onmiddellik gevangenisstraf opgele te word. Wat ookal besluit mag word, skyn dit of die ondersteunende maar ook die regsprofessie nog nie duidelikheid het van wat die korrekte optrede behoort te wees nie. Conte (1984:563) wys daarop dat hy in sy ondersoek gevind het dat in die meeste van die gevalle waar die kind uit die gesin verwyder is, die kind dit as 'n strafmatreël beleef het. Hy beweer verder dat die lewe van die kind net verder ontwrig word en dat hy ontneem word van moontlike emosionele onderskraging vanuit die gesinsisteem.

In sy ondersoek het Conte (1984:634) oorwegend gevind dat gevangenisstraf nie altyd tot voordeel van die gesin strek nie. Die probleem word net vir'n verdere tydperk uitgestel asook die moontlikheid om met terapie te begin ten einde die gesin te help om te verander. Daar bestaan tans ook kommer oor die struktuur van die gevangenisstelsel waarbinne seksuele molestering behandel moet word.

'n Relevante vraag wat gevra kan word is of daar binne die onderskeie gevangenisse, met inagneming van die besondere milieu, spesifieke rehabilitasieprogramme vir seksuele oortreders bestaan, en of die vader of oortreder slegs uit die gemeenskap verwyder word om na vrylating daarheen terug te keer - steeds met 'n onopgeloste probleem. Conte \& Shore (1982:13) wys daarop dat maatskaplike werkers nie tyd het om op die debattering van die dilemma (moet 'n klag gelê word of nie) te verspil nie, maar dat daar eerder onmiddellik met hulpverlening aan die betrokkenes begir. moet word.

\section{GEVOLGTREKKING}

Alhoewel dit alle professionele persone wat met seksuele molestering gekonfronteer is se uitgangspunt is om ten alle tye die kind se belange te beskerm, blyk dit of laasgenoemde nie so 'n eenvoudige taak is nie. Vanuit die inligting wat in hierdie artikel gekonstrueer is, kom die skrywer tot die volgende gevolgtrekkings hoewel daar geensins aanspraak daarop gemaak word dat hierdie inligting veralgemeen kan word nie:

* Die behandeling van seksuele molestering vereis intensiewe terapeutiese werk. 
* Daar bestaan tans weinig hulpbronne waarheen die gesin waarbinne molestering voorkom, kan gaan aanklop vir hulp sonder die vrees vir veroordeling. So 'n hulpbron kan ook vir ander professionele persone 'n bron van ondersteuning en konsultasie wees.

* Met die bekendmaking van seksuele molestering word daar oor die algemeen baie verskillende professies wat elk hul eie betekenis aan die probleem heg, betrek. Hierdie situasie bring egter mee dat hierdie persone verskillend met die kind en sy gesin kan werk en sodoende verwarring by laasgenoemde kan bewerkstellig. Fragmentering van dienste kan dus ook plaasvind.

* As gevolg van verskillende faktore bestaan daar oorwegend weersin by die hulpprofessies ten opsigte van seksuele molestering. Hierdie ingesteldheid bring mee dat die behandeling van sodanige gesinne nie tot sy reg kom nie.

- Die professionele persoon is nie altyd oortuig of dit in belang van ' $n$ kind is om in hofsake betrek te word nie. Die blootstelling aan die hofprosedures kan soms' $n$ traumatiese ervaring vir die kind en die gesin wees wat verdere gesinsdisintegrasie in die hand kan werk. 'n Gebrek aan kennis van die regsproses by persone in die hulpprofessies kan ook daartoe lei dat kinders nie doeltreffend vir hofverrigtinge voorberei word nie.

\section{AANBEVELINGS}

Voortvloeiend uit bogenoemde kan die volgende aanbevelings gemaak word as moontlike riglyne vir die hantering van seksuele molestering:

- Professionele persone wat met seksuele molestering werk, behoort gespesialiseerde opleiding in hierdie verband te ontvang. Maatskaplike werkers met hierdie opleiding kan in gespesialiseerde poste binne diensorganisasies aangestel word. Die verskillende opleidingsinstellings behoort die praktyk in hierdie verband te ondersteun.

- Hulpbronne wat spesifiek 'n gespesialiseerde diens aan die gemeenskap ten opsigte van seksuele molestering kan bied, behoort tot stand te kom. Nie net die gesin kan daar behandeling ontvang nie, maar dit kan ook die funksie van opleiding en konsultasie aan professionele persone bied. Behandeling by so 'n hulpbron kan ook'n alternatief vir gevangenisstraf wees.

* Persone van verskillende hulpprofessies behoort ook in die regsproses opgelei te 
word - veral met die lewering van deskundige getuienis. Die probleem behoort veral by die opleiding van die maatskaplike werker ondervang te word.

* Beter samewerking tussen die verskillende professies tydens die hantering van seksuele molestering behoort dringend aandag te geniet. 'n Sisteem behoort gevorm te word waarbinne hierdie verskillende professies op 'n nie-gefragmenteerde wyse kan saamwerk. Die skrywer het tans nie 'n oplossing om hierdie nuwe sisteem te vorm nie, maar sien dit as die volgende stap in die ontdekkingstog van gesinne waarbinne seksuele molestering voorkom.

* Verdere navorsing behoort onderneem te word om steeds inligting ten opsigte van seksuele molestering vry te stel. Die realiteit dat seksuele molestering in strafhowe verhoor word, moet verdere aandag geniet.

\section{BIBLIOGRAFIE}

CONTE, J.R. 1984. The justice system and scxual abuse of children. Social Service Review, 58(5):556567.

CONTE, J.R. \& Shore, D.A. 1982. Social work and child sexual abuse. New York : The Haworth Press. EFRAN, J., LUKENS, R.J. \& LUKENS, M.D. 1988. Toward a "Second Order". Family systems theory. Family Systems Medicine, 3(4):381-396.

HOFFMAN, L. \& LONG. 1969. A systems dilemma. Family Process, 8:211-234.

HUSAIN, A. JAMES \& CHAPEL, J.L. 1983. History of incest in girls admitted to a psychiatric hospital American Joumal of Psychiairy, 140(5):591-592.

JUSTICE, B. \& JUSTICE, R. 1979. The broken taboo. London : Peter Owen Limited.

LEGENDRE, D. 1986. An investigation of father-daughter incest from a family-systems perspective: Its causes and treatment, and the unique contribution of pastoral care to incest therapy. Michigan : UMI.

LE ROUX, P. 1987. Autonomy and competence in families with a child at risk: An ecosystemic approach. Pretoria. (Ongepublisecrde D Phil - UNISA.)

PALAZOLLI, M.S., BOSCOLO, L., CECCHIN, G. \& PRATA, G. 1980. Hypothesizing - circularity neutrality: The guidelines for the conductor of the session. Family Process, 19:3-12.

SWANSON, L. \& BIAGGIO, M.K. 1985. Therapeutic perspectives on father-daughter incest. The Anterican Joumal of Psychiaty, 142(6):667-673.

TREPPER, T.S. \& BARRETT, M. 1989. Systcmic trcatment of incest. New York : Brunner/Mazel. Publishers. 


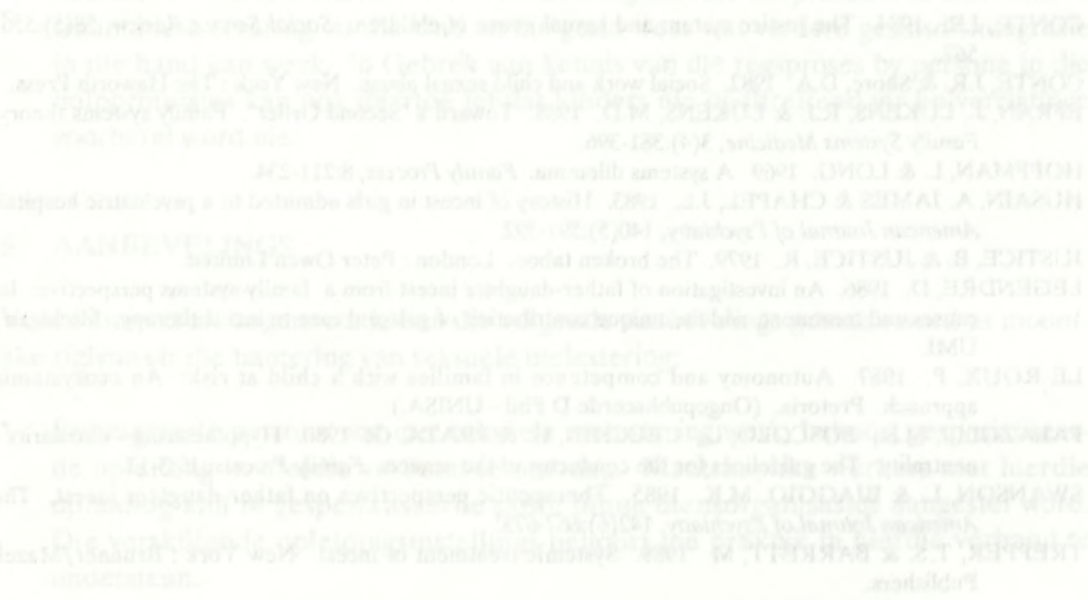

